\title{
Autoimmune disease in mothers with the FMR1 premutation is associated with seizures in their children with fragile $\mathrm{X}$ syndrome
}

\author{
Weerasak Chonchaiya $\cdot$ Flora Tassone $\cdot$ Paul Ashwood $\cdot$ \\ David Hessl • Andrea Schneider $\cdot$ Luis Campos • \\ Danh V. Nguyen · Randi J. Hagerman
}

Received: 16 June 2010 / Accepted: 23 August 2010 / Published online: 1 September 2010

(c) The Author(s) 2010. This article is published with open access at Springerlink.com

\begin{abstract}
An increased prevalence of autoimmune diseases in family members of children with autism spectrum disorders (ASD) has been previously reported. ASD is also a common problem co-occurring in children with fragile $\mathrm{X}$ syndrome (FXS). Why ASD occurs in some individuals with FXS, but not all, is largely unknown. Furthermore, in premutation carrier mothers, there is an increased risk for autoimmune diseases. This study compared the rate of ASD and other neurodevelopmental/behavioral problems in 61 children with FXS born to 41 carrier mothers who had autoimmune disease and in 97 children with FXS of 78 carrier mothers who did not have autoimmune disease. There were no significant differences in the mean age $(9.61 \pm 5.59$ vs. $9.41 \pm 6.31, P=0.836$ ), cognitive and adaptive functioning in children of mothers with and without autoimmune disease. Among children whose mothers had autoimmune disease, the odds ratio (OR) for ASD was 1.27 (95\% CI $0.62-2.61, P=0.5115)$. Interestingly, the $\mathrm{OR}$ for seizures and tics was $3.81(95 \% \mathrm{CI} 1.13-12.86, P=0.031)$ and 2.94
\end{abstract}

\footnotetext{
W. Chonchaiya $\cdot$ F. Tassone $\cdot$ P. Ashwood - D. Hessl ·

A. Schneider · R. J. Hagerman ( $\square)$

Medical Investigation of Neurodevelopmental

Disorders (MIND) Institute, University of California

Davis Health System, 2825 50th Street, Sacramento,

CA 95817, USA

e-mail: randi.hagerman@ucdmc.ucdavis.edu

W. Chonchaiya

Division of Growth and Development,

Department of Pediatrics, Faculty of Medicine,

King Chulalongkorn Memorial Hospital,

Chulalongkorn University, Bangkok, Thailand

F. Tassone

Department of Biochemistry and Molecular Medicine,

School of Medicine, University of California Davis,

Davis, CA, USA
}

(95\% CI 1.19-7.24, $P=0.019$ ), respectively, in children of mothers with autoimmune disease compared to children of mothers without autoimmune disease. In conclusion, autoimmune disease in carrier mothers was not associated with the presence of ASD in their children. However, seizures and tics were significantly increased in children of mothers with autoimmune disease. This suggests a potential new mechanism of seizure and tic exacerbation in FXS related to an intergenerational influence from autoimmunity in the carrier mother.

\section{Introduction}

There is a close connection between immune function and development of the central nervous system (CNS). Both systems interact across the life span of an individual so that successful neurodevelopment requires a normal balance of immune responses (Ashwood et al. 2006; Delneste et al.

\footnotetext{
P. Ashwood

Department of Medical Microbiology and Immunology,

School of Medicine, University of California Davis,

Davis, CA, USA

D. Hessl · A. Schneider

Department of Psychiatry and Behavioral Sciences,

University of California Davis Health System,

Sacramento, CA, USA

L. Campos · D. V. Nguyen

Division of Biostatistics,

Department of Public Health Sciences, School of Medicine,

University of California Davis, Davis, CA, USA

R. J. Hagerman

Department of Pediatrics, University of California Davis

Health System, Sacramento, CA, USA
} 
1999). Autism spectrum disorders (ASD) are a complex group of heterogeneous neurodevelopmental disorders with significant social and communication deficits in which etiologies are mostly unknown. Recently, altered immunogenetics and a dysfunctional immune system have been proposed to play a role in at least a subgroup of children with ASD (Ashwood et al. 2006; Enstrom et al. 2009). In addition, an increased prevalence of autoimmune disease in family members of children with idiopathic ASD has been demonstrated in several studies (Atladottir et al. 2009; Comi et al. 1999; Money et al. 1971; Sweeten et al. 2003). Maternal autoantibodies may also affect fetal brain development during critical periods of neurodevelopment in a subset of children with ASD (Ashwood and Van de Water 2004; Dalton et al. 2003; Singer et al. 2006). Studies have shown that when IgG from mothers of children diagnosed with ASD is injected into pregnant rhesus monkeys, there are behavioral changes in the rhesus offspring including abnormal stereotypical and hyperactive behaviors, compared with offspring injected with $\mathrm{IgG}$ isolated from mothers of typically developing children and controls (Martin et al. 2008). These findings suggest a potential deleterious relationship between exposure to autoantibodies against the fetal brain during gestation and the risk to develop ASD.

Fragile X syndrome (FXS) is the most common known single gene cause of autism (Hagerman et al. 2008). The prevalence of autism in individuals with FXS is approximately 30\% (Kaufmann et al. 2004; Rogers et al. 2001) and pervasive developmental disorder-not otherwise specified (PDD-NOS) is seen in an additional 30\% (Harris et al. 2008). Therefore, the prevalence of ASD is approximately $60 \%$ in individuals with FXS (Hagerman et al. 2008; Harris et al. 2008). The mechanism of ASD in FXS is hypothesized to be related to the deficit of FMRP (the FMR1 protein) which regulates the translation of many genes that are associated with autism (Chonchaiya et al. 2009; Hagerman et al. 2008; Wang et al. 2010). Why ASD occurs in some individuals with FXS, but not all, is largely unknown (Loesch et al. 2007). Problems affecting the CNS including seizures, malformations, or other genetic disorders are more likely to occur in those with FXS and ASD compared with those with FXS without ASD (Garcia-Nonell et al. 2008). Therefore, the diagnosis of ASD in those with FXS may also be related to additional risks including genetic and environmental factors leading to additional brain dysfunction additive to the FMRl mutation (Loesch et al. 2007).

The prevalence of autoimmune diseases including autoimmune thyroid disease, lupus, multiple sclerosis (MS), and fibromyalgia (with a postulated autoimmune component) are increased in females with the FMRI premutation (Buskila and Sarzi-Puttini 2008; Coffey et al. 2008; Di Franco et al. 2010; Greco et al. 2008; Rodriguez-Revenga et al. 2009; Staines 2004; Zhang et al. 2009). These autoim- mune disorders in some premutation carriers are thought to be related to RNA toxicity from elevated levels of FMRI mRNA (Coffey et al. 2008; Greco et al. 2008; Zhang et al. 2009). Maternal autoimmunity may play an additional role that further contributes to ASD or may be associated with more severe ASD symptoms along the continuum of social deficits in their children with FXS. However, the association between autoimmune disease in mothers and the presence of ASD or other medical and behavioral problems particularly tics [since tics and Tourette syndrome have a potential autoimmune etiology through the mechanism of pediatric autoimmune neuropsychiatric disorders associated with streptococcal infection (PANDAS) (Martino et al. 2009a)] that perhaps could be influenced by autoimmunity in their children with FXS has not been studied previously. We therefore investigated whether autoimmune diseases/ conditions in mothers with the FMRI premutation are associated with ASD or other problems by comparing the offspring of mothers with and without autoimmune disease $(\mathrm{M}+\mathrm{AI}$ and $\mathrm{M}-\mathrm{AI})$.

\section{Materials and methods}

Subjects

Included in this study were children with FXS $(n=158)$ with either the full mutation or mosaicism, and their mothers $(n=119)$ whom were seen between 2003 and 2009 at the MIND Institute. This study was approved by the Institutional Review Board of the University of California, Davis. The children with FXS in this cohort were divided into children $(n=61)$ who were born to mothers who had a history of autoimmune disease and children $(n=97)$ whose mothers did not have autoimmune disease.

The diagnosis of autoimmune disease in the mother was confirmed by a physician and these diseases include autoimmune thyroid disease, systemic lupus erythematosus (SLE), rheumatoid arthritis, multiple sclerosis (MS), Sjogren's syndrome, psoriasis, optic neuritis, Raynaud's phenomenon, or fibromyalgia, which has a postulated autoimmune component in its pathophysiology (Coffey et al. 2008; Di Franco et al. 2010; Greco et al. 2008; Staines 2004; Zhang et al. 2009). Sixty-one children with FXS with a mean age of 9.61 years (SD 5.59) were born to 41 mothers with a mean age of 40.54 years (SD 7.96) who had experienced autoimmune disease. They were compared to 97 children with FXS with a mean age of 9.41 years (SD 6.31 ), born to 78 mothers with a mean age of 38.62 years (SD 6.46) without a history of clinically defined autoimmune disease. Most mothers in each group $[\mathrm{M}+\mathrm{AI}$ and M - AI, 23 (56.1\%) vs. 59 (75.6\%), respectively] had one child with FXS. There were $16(39.0 \%)$ and $19(24.4 \%)$ 
$\mathrm{M}+\mathrm{AI}$ and $\mathrm{M}-\mathrm{AI}$, respectively, who had two children with FXS. Two (4.9\%) M + AI had three children with FXS. Children with the FMRI premutation born to these mothers were not included in the study. A description of both mothers and children with FXS are presented in Tables 1 and 2 .

\section{Study protocol}

All subjects underwent a full medical history and physical examination by a physician with expertise in fragile $\mathrm{X}$-associated disorders (RJH) after informed consent was obtained. The medical history covered an extensive review of prenatal, perinatal and postnatal history and complications, developmental and behavioral variations and problems for each child including developmental delay or regression of development, tics (a sudden, repetitive, nonrhythmic, stereotyped motor movement or vocalization involving discrete muscle groups, such as eye blinking, shoulder shrugging, throat clearing, etc.; tics symptoms had to appear before 18 years of age and occur before taking stimulant medications if those with FXS also have co-morbid attention deficit/hyperactivity disorders), sleep problems (problems falling asleep or waking up at night), clinical seizures (seizures characteristics, onset, duration, frequency, any co-occurring loss of consciousness, other neurological deficit, associated symptoms, possible triggers if they could be defined, electrical activity recorded by an electroencephalography (EEG) testing, and anticonvulsant medications), other pertinent medical problems, review of systems, and medications. Autoimmune diseases/conditions in mothers were thoroughly obtained by self-report after questioning about all potential autoimmune disorders in the medical history mentioned above. Sometimes medical records (approximately 30\%) of the mothers were available for review in those with autoimmune problems during the visits at our clinic; however, these data are not included in the analysis because it was not consistently obtained. To be documented as having an autoimmune disease in the mother or developmental, behavioral, and medical problems particularly seizures, tics, and sleep problems in children with FXS, the subjects had to have sought medical or pediatric professional help for their problems and to have been previously diagnosed and/or treated by a physician for each disease/condition (physician-documented clinical involvement). Each subject underwent a medical examination
Table 1 Characteristics of mothers with the fragile $\mathrm{X}$ premutation

Table 2 Characteristics of children with FXS

* Significant at 0.05 level

\begin{tabular}{|c|c|c|c|c|}
\hline Variables & $\begin{array}{l}\text { Mother with } \\
\text { autoimmune disease }^{1} \\
\text { Mean (SD) }\end{array}$ & $\begin{array}{l}\text { Mother without } \\
\text { autoimmune disease } \\
\text { Mean (SD) }\end{array}$ & $N^{1} / N^{0}$ & $P$ \\
\hline $\begin{array}{l}\text { Age (years) } \\
\text { Age range }\end{array}$ & $\begin{array}{l}40.54(7.96) \\
(30-66)\end{array}$ & $\begin{array}{l}38.62(6.46) \\
(24-58)\end{array}$ & $41 / 78$ & 0.238 \\
\hline CGG repeats & $97.59(20.31)$ & $96.30(23.05)$ & $27 / 60$ & 0.687 \\
\hline Activation ratio & $0.57(0.14)$ & $0.56(0.17)$ & $26 / 54$ & 0.146 \\
\hline FMR1 mRNA & $2.74(0.75)$ & $2.55(0.78)$ & $24 / 44$ & 0.773 \\
\hline
\end{tabular}

\begin{tabular}{lllll}
\hline Variables & $\begin{array}{l}\text { Children of mothers } \\
\text { with autoimmune } \\
\text { disease } \\
\text { Mean (SD) }\end{array}$ & $\begin{array}{l}\text { Children of mothers } \\
\text { without autoimmune } \\
\text { disease } \\
\text { Mean (SD) }\end{array}$ & $N^{1} / N^{0}$ & $P$ \\
\hline $\begin{array}{l}\text { Age (years) } \\
\text { Age range }\end{array}$ & $9.61(5.59)$ & $9.41(6.31)$ & & \\
Male & $(1.5-24)$ & $(0.92-25.17)$ & $61 / 97$ & 0.836 \\
Type of fragile X mutation (\%) & $60.7 \%$ & $78.4 \%$ & $61 / 97$ & $0.016^{*}$ \\
$\quad$ full mutation:mosaicism & $48: 13(78.7: 21.3)$ & $77: 20(79.4: 20.6)$ & $61 / 97$ & 0.876 \\
CGG repeat levels & $651.30(246.98)$ & $732.49(321.52)$ & $33 / 65$ & 0.207 \\
mRNA levels & $1.10(0.92)$ & $1.05(1.64)$ & $10 / 37$ & 0.927 \\
Full scale IQ & $62.75(17.77)$ & $60.80(17.55)$ & $56 / 83$ & 0.523 \\
Vineland-II & & & & \\
Adaptive behavioral composite & $64.33(18.51)$ & $63.62(18.71)$ & $42 / 66$ & 0.847 \\
Communication & $69.05(20.58)$ & $66.52(21.00)$ & $41 / 67$ & 0.542 \\
Daily living skills & $64.76(21.92)$ & $64.90(21.48)$ & $41 / 67$ & 0.974 \\
Socialization & $69.20(15.70)$ & $69.42(15.86)$ & $41 / 67$ & 0.943 \\
Motor & $73.14(14.84)$ & $72.09(17.36)$ & $21 / 35$ & 0.817 \\
\hline
\end{tabular}


that included a head circumference. A large head or macrocephaly was defined as exceeding 2 standard deviations (SD) above normal when compared with typically developing children of the same age.

The diagnosis of ASD in those with FXS was made after the use of standardized measures including the Autism Diagnostic Observation Schedule (ADOS), the Autism Diagnostic Interview, Revised (ADI-R) and the Diagnostic and Statistical Manual of Mental Disorders (DSM IV) (American Psychiatric Association 2000; Le Couteur et al. 1989; Lord et al. 2000) followed by a team consensus discussion as previously described (Harris et al. 2008).

The developmental or cognitive abilities were assessed with age appropriate measures, including the Mullen Scales of Early Learning, the Wechsler Preschool and Primary Scale of Intelligence-Third Edition (WPPSI-III), the Wechsler Intelligence Scale for Children-Third Edition (WISC-III), the Wechsler Intelligence Scale for ChildrenFourth Edition (WISC-IV), the Wechsler Abbreviated Scale of Intelligence (WASI), the Wechsler Adult Intelligence Scale-Third Edition (WAIS-III) or the StanfordBinet Intelligence Scale, Fourth Edition. Children's adaptive functioning was also assessed using the Vineland Adaptive Behavioral Scales, Second Edition (Vineland-II) by interviewing the caregivers (Mullen 1995; Sparrow et al. 2005; Thorndike et al. 1986; Wechsler 1991, 1997, 1999, 2002, 2003). Intellectual disability was defined as IQ less than 70 .

Behavioral and emotional problems including externalizing behaviors (hyperactivity, aggression, and conduct problems), internalizing behaviors (anxiety, depression, and somatization), atypicality, withdrawal, attention problems, and adaptive skills (adaptability, social skills, leadership, activities of daily living, and functional communication) were completed by a limited percentage of parents for each group of children with FXS (autoimmune disease vs. no autoimmune disease, 72.1 vs. $54.6 \%$ ) using Behavior Assessment System for Children (BASC) questionnaire (Reynolds and Kamphaus 1992, 2004). Behavior Symptoms Index (BSI), a measure of an overall level of problems consisting of the hyperactivity, aggression, depression, attention problems, atypicality and withdrawal scales, was also documented. The BASC parent rating scale yields $T$ scores with a mean of 50 and a SD of 10 . On the clinical scales, scores from 60 to 69 are in the "at-risk" range and scores of 70 and above indicate "clinically significant" problems. On the adaptive skill scales of the BASC, scores from 31 to 40 indicate "at-risk" problems and scores of 30 and lower are considered "clinically significant." In this study, externalizing, internalizing behaviors, and BSI scores 60 or above were defined as having those problems accordingly, whereas deficits in adaptive skills were defined in which adaptive skills scores are 40 or lower. Table 3 lists the variables investigated statistically between both groups of children.

Molecular analysis

A blood sample for measurement of methylation status, CGG repeat, and FMR1 mRNA levels were obtained from each subject (both mothers and children with FXS). FMRI mRNA quantification, Southern Blot and PCR-based

Table 3 Neurodevelopmental and behavioral problems between both groups of children

\begin{tabular}{|c|c|c|c|c|c|c|}
\hline Variables & $\begin{array}{l}\text { Children of mothers } \\
\text { with autoimmune } \\
\text { disease }^{1}\end{array}$ & $\begin{array}{l}\text { Children of mothers } \\
\text { without autoimmune } \\
\text { disease }^{0}\end{array}$ & $N^{1} / N^{0}$ & $P$ & $\begin{array}{l}\text { Odds } \\
\text { ratio }\end{array}$ & $95 \% \mathrm{CI}$ \\
\hline ASD diagnosis & $38(62.3 \%)$ & $56(57.73 \%)$ & $61 / 97$ & 0.5115 & 1.27 & $0.62-2.61$ \\
\hline Autism & $22(36.07 \%)$ & $31(31.96 \%)$ & & & & \\
\hline PDDNOS & $16(26.23 \%)$ & $25(25.77 \%)$ & & & & \\
\hline Intellectual disability & $41(68.33 \%)$ & $75(78.13 \%)$ & $60 / 96$ & 0.1464 & 0.59 & $0.29-1.2$ \\
\hline \multicolumn{7}{|l|}{ BASC } \\
\hline Externalizing behaviors & $16(36.36 \%)$ & $9(16.98 \%)$ & $44 / 53$ & $0.0319 *$ & 3.04 & $1.10-8.38$ \\
\hline Internalizing behaviors & $13(29.55 \%)$ & $8(15.09 \%)$ & $44 / 53$ & 0.1081 & 2.29 & $0.83-6.31$ \\
\hline BSI & $31(72.09 \%)$ & $29(55.77 \%)$ & $43 / 52$ & $0.1045^{\mathrm{a}}$ & 2.04 & $0.86-4.8$ \\
\hline Deficits in adaptive skills & $32(72.73 \%)$ & $39(73.58 \%)$ & $44 / 53$ & 0.9101 & 0.95 & $0.37-2.43$ \\
\hline Seizures & $9(15 \%)$ & $4(4.21 \%)$ & $60 / 95$ & $0.031 *$ & 3.81 & $1.13-12.86$ \\
\hline Sleep problems & $24(42.86 \%)$ & $35(38.04 \%)$ & $56 / 92$ & 0.6626 & 1.17 & $0.58-2.38$ \\
\hline Tics & $15(25.86 \%)$ & $10(10.64 \%)$ & $58 / 94$ & $0.019 *$ & 2.94 & $1.19-7.24$ \\
\hline Macrocephaly & $4(7.14 \%)$ & $7(7.53 \%)$ & $56 / 93$ & 0.9531 & 0.96 & $0.23-3.97$ \\
\hline
\end{tabular}

* Significant at 0.05 level

${ }^{\text {a }}$ Results are similar for all analyses with gender, except for BSI where $P=0.0225$ 
genotyping were performed as previously described (Tassone et al. 2000; Tassone et al. 2008).

\section{Statistical analysis}

Qualitative variables for which there were specified cut-offs including autoimmune disease in mothers, the diagnosis of ASD, intellectual disability, seizures, sleep problems, tics, macrocephaly, externalizing, internalizing behaviors, BSI and deficits in adaptive skills were rated dichotomously (presence or absence) as demonstrated in Table 3. Univariate analysis of continuous variables including age, CGG repeat size, FMRI mRNA level, activation ratio (AR: the fraction of normal FMRI allele as the active allele in female individuals with FXS), IQ, and adaptive functioning was based on $t$ test. Fisher's exact test for $2 \times 2$ contingency table analyses were used to assess the association between autoimmune status in the mothers of children with FXS and the diagnosis of ASD. Results are presented in terms of odds ratio (OR) and 95\% confidence interval $(95 \% \mathrm{CI}) . P$ value and $95 \%$ confidence interval (CI) relating to the primary hypotheses of whether there is an association of autoimmune disease in mothers to ASD in children with FXS was based on a logistic regression model using generalized estimating equations. This approach accounts for correlation within a family (i.e. mother-children correlation) in estimates of standard errors, although this did not make a material difference in the results. Also, models were explored with adjusting for mother's age, child's age, gender, number of offspring, whether a mother had a child before or after age 35, CGG repeat numbers, and mRNA levels. All covariates were not significant and adjusted OR estimates did not differ from OR estimates from models with only the main variable of interest-the presence of autoimmune disease. Thus, we reported this simple later model with main effect of interest. An exception is for the variable gender in the model of BSI outcome (as noted in Table 3; see "Results"). However, we did not adjust for multiple testing and the reason for this is that our original primary hypothesis relates to investigating the association between autoimmune disease in the mothers and ASD. Neurodevelopmental and behavioral outcomes, particularly the collection of BASC variables, were exploratory. BASC $T$ scores were analyzed using general linear model adjusted for age and accounting for within-in family correlation and variation among subjects. All $P$ reported are two-sided and the significance level is 0.05 .

\section{Results}

\section{Characteristics of subjects}

Characteristics of the mothers and their offspring with FXS are illustrated in Tables 1 and 2, respectively. There was no significant difference in mean age between $\mathrm{M}+\mathrm{AI}$ and M - AI [40.54 (SD 7.96) vs. 38.62 (SD 6.46) years, $P=0.238]$. There were no significant differences in molecular variables including CGG repeats, FMR1 mRNA levels, and AR between both groups of mothers. The two most common autoimmune disorders in the mothers were autoimmune thyroid diseases $(27 / 41,65.9 \%)$, and fibromyalgia (11/41, 26.8\%). MS and Raynaud's phenomenon were present at a similar rate in the mothers at $12.2 \%(5 / 41)$. Four $(4 / 41,9.8 \%)$ mothers reported to have been diagnosed with rheumatoid arthritis and three $(3 / 41,7.3 \%)$ mothers reported having SLE. Other reported autoimmune diseases included Sjogren syndrome (1/41), optic neuritis (1/41), and psoriasis for each disease $(1 / 41)$. Of the $41 \mathrm{M}+\mathrm{AI}$, there were 29 who presented with a single autoimmune disease, whereas a further 12 reported having two or more autoimmune diseases. Twenty $(48.8 \%)$ mothers had autoimmune thyroid disease alone and $3(7.3 \%)$ mothers had been diagnosed with fibromyalgia alone. In 23 (56.1\%) mothers, the mean age of diagnosis with autoimmune disease was 30.26 (SD 9.45) years. The remainder of the group neither recalled the onset of the autoimmune disease nor the data for the onset of autoimmune disease in medical records were collected before the association between autoimmune disease in the mothers and the presence of ASD in their offspring with FXS was hypothesized.

Of the 41 mothers, 13 stated that their autoimmune disease occurred during their gestation. However, a precise ascertainment of the age of onset or diagnosis for each autoimmune disease based on self-report was very difficult due to the fact that the natural course of many autoimmune diseases can include a subclinical phase that does not meet stringent clinical diagnosis (Papi et al. 2007; Poppe and Glinoer 2003; Ulff-Moller et al. 2009).

There was significant difference neither in the mean age of children with FXS in the two groups [9.61 (SD 5.59) vs. 9.41 ( $\mathrm{SD}$ 6.31) years, in children born of $\mathrm{M}+\mathrm{AI}$ and $\mathrm{M}-\mathrm{AI}$, respectively, $P=0.836$ ] nor in the type of the fragile $\mathrm{X}$ mutation (percentage of full mutation/ mosaic $=78.7 / 21.3 \%$ vs. $79.4 / 20.6 \%, P=0.876]$. With regard to gender, there were fewer male children with FXS born to $\mathrm{M}+\mathrm{AI}$ when compared with children with FXS of $\mathrm{M}-\mathrm{AI}(60.7$ vs. $78.4 \%, P=0.016)$. Mean cognitive ability in both groups of children with FXS was in a mild range of intellectual disability and was not significantly different between groups [FSIQ $=62.75$ (SD 17.77) vs. 60.80 (SD 17.55), in children born of $\mathrm{M}+\mathrm{AI}$ and $\mathrm{M}-\mathrm{AI}$, respectively, $P=0.523$ ]. Likewise, the adaptive behavior composite score documented by the Vineland between both groups of children with FXS was not significantly different [64.33 (SD 18.51) vs. 63.62 (SD 18.71), in children born of $\mathrm{M}+\mathrm{AI}$ and $\mathrm{M}-\mathrm{AI}$, respectively, $P=0.847]$. 
Autoimmune disease, ASD, and other neurodevelopmental problems

Of the 61 children with FXS born to $\mathrm{M}+\mathrm{AI}, 38(62.3 \%)$ children met the criteria for ASD. Twenty-two (36.07\%) subjects had autism and $16(26.23 \%)$ had PDD-NOS. Of the 32 mothers with children that had FXS and ASD, autoimmune thyroid disease was present in 22 (67.6\%), fibromyalgia in $8(25.0 \%)$, and Raynaud's phenomenon in 4 (12.5\%). Among children from $\mathrm{M}+\mathrm{AI}$, the odds ratio (OR) for FXS and ASD was 1.27 (95\% CI 0.62-2.61, $P=0.5115)$. These data suggest that autoimmune disease in the mothers may not be a relevant risk factor for autism in combination with FXS. Other variables including intellectual disability, sleep problems, and macrocephaly were not different between both groups of children. However, the rate of tics was significantly higher in the group of children with FXS born to M + AI $(15 / 58,25.86 \%)$ compared with $\mathrm{M}-\mathrm{AI}[10 / 94,10.64 \%$; OR = 2.94 (95\% CI 1.19-7.24), $p=0.019]$.

\section{Autoimmune disease and seizures}

Data about seizures were not available for three children. However, a higher rate of clinical seizures was observed in a group of children with FXS born to M + AI (9/60, $15.0 \%$ ) when compared with children with FXS of $\mathrm{M}-\mathrm{AI}[4 / 95,4.21 \%$; OR $=3.81$ (95\% CI 1.13-12.86), $P=0.031]$. Details of the nine children with FXS who have seizures and were born to $\mathrm{M}+\mathrm{AI}$ are as follows: age range, 4.17-24 years (median age 9 years); gender, 7 boys and 2 girls; FMR 1 mutations, six have the full mutation and three have mosaicism in the FMRl gene. Three have more than one seizures type including complex partial seizures, generalized seizures, gelastic seizures and absence seizures, four had generalized tonic-clonic convulsions alone, and two experienced petit mal or absence seizures alone. Seizures onset ranged from 17 months to 9 years with a median age of onset at 3 years. With regard to treatment of seizures, seven subjects reported to take long-term anticonvulsant medications. Four of these seven subjects took more than one anticonvulsants to control the seizures. Of these nine children with FXS born to $\mathrm{M}+\mathrm{AI}$ who developed clinical seizures, eight mothers had autoimmune thyroid disease. There was no history of birth asphyxia or neonatal encephalopathy. The cognitive abilities of children with seizures were similar to the whole group of children with FXS.

Details of four children with FXS who had seizures born to $\mathrm{M}-\mathrm{AI}$ are as follows: age range $3.63-17.75$ years (median age 8.25 years), gender 3 boys and 1 girl, all have the full mutation in the FMRI gene; one reported to have more than one seizure type including absence, complex partial seizures, and generalized seizures, one experienced absence seizures alone, one had partial seizures alone, and one subject was noted to have two episodes of simple febrile seizures but this child has never taken any medications. Seizures onset in this group ranged from 2.67 to 5 years with a median age of onset at 3.84 years. Abnormal EEG results were confirmed in all subjects in this group of children. With regard to anticonvulsant medications, one child has taken more than one medication to treat the seizures and seizures were well controlled by one medication in two subjects in this group.

\section{Autoimmune disease and behavioral problems}

Behavioral and emotional problems documented by BASC were completed in $97(61.4 \%)$ children with FXS in our study. The children's age, gender and type of the fragile $\mathrm{X}$ mutations were not significantly different between both groups (children of $\mathrm{M}+\mathrm{AI}$ and $\mathrm{M}-\mathrm{AI}$ ). The rate of externalizing behaviors [36.36 vs. 16.98\%; OR $=3.04$ (95\% CI 1.10-8.38), $P=0.0319]$ was increased in children with FXS born to $\mathrm{M}+\mathrm{AI}$. $T$ scores of these behavioral and emotional problems between both groups of children are illustrated in Table 4. Children with FXS born to $\mathrm{M}+\mathrm{AI}$ were likely to have higher $T$ scores on aggression, internalizing behaviors, depression, withdrawal symptoms, and BSI when compared with those children with FXS born to M - AI, even though only withdrawal symptoms and BSI scale reached a significant level for documenting the problems.

\section{Discussion}

This is the first study investigating the intergenerational association between the presence of co-morbid ASD, medical problems, and behavioral problems in the children with FXS of M + AI. Evidence of an increased prevalence of autoimmune disorders including hypothyroidism, Hashimoto's thyroiditis, type 1 diabetes, rheumatoid arthritis, SLE and ulcerative colitis have been reported in parents of children with idiopathic ASD in previous studies (Atladottir et al. 2009; Comi et al. 1999; Croen et al. 2005; Money et al. 1971; Mouridsen et al. 2007; Sweeten et al. 2003). However, this finding was not replicated in all studies (Micali et al. 2004). Our clinical sample of children with FXS did not support this finding. Therefore, autoimmunity in the mothers may not be significantly associated with ASD in the offspring with FXS. A mutation in the FMRI gene alone involves significant dysregulation of numerous genes whose translation is controlled by FMRP leading to significant deficits in synaptic plasticity and ASD (Chonchaiya et al. 2009). 
Table 4 Parent rating scale ( $T$ score) of behavioral and emotional problems documented by BASC between both groups of children

\begin{tabular}{lclll}
\hline Variables & $\begin{array}{l}\text { Children of mothers } \\
\text { with autoimmune } \\
\text { diseases } \\
\text { Mean (SD) }\end{array}$ & $\begin{array}{l}\text { Children of mothers } \\
\text { without autoimmune } \\
\text { diseases } \\
\text { Mean (SD) }\end{array}$ & $N^{1} / N^{0}$ & $P$ \\
& $56.5(12.75)$ & $52.45(9.02)$ & & \\
\hline Externalizing problems & $62.64(14.22)$ & $61.83(11.36)$ & $44 / 53$ & 0.072 \\
Hyperactivity & $51.68(12.96)$ & $45.57(7.77)$ & $44 / 53$ & 0.757 \\
Aggression & $50.13(12.79)$ & $45.81(10.37)$ & $34 / 53$ & $0.005^{*}$ \\
Conduct problems & $55.14(11.49)$ & $49.85(10.02)$ & $44 / 53$ & 0.104 \\
Internalizing problems & $52.7(13.82)$ & $48.51(10.28)$ & $44 / 53$ & $0.016^{*}$ \\
Anxiety & $55.07(9.7)$ & $50.87(11.14)$ & $44 / 53$ & $0.049 *$ \\
Depression & $55.34(14.08)$ & $50.55(10.01)$ & $44 / 53$ & 0.053 \\
Somatization & $68.23(15.26)$ & $65.69(14.66)$ & $43 / 52$ & 0.405 \\
Atypicality & $73.36(11.9)$ & $65.21(12.97)$ & $44 / 53$ & $0.001^{*}$ \\
Withdrawal & $66.64(12.98)$ & $65.57(10.33)$ & $44 / 53$ & 0.654 \\
Attention problems & $33.82(10.91)$ & $34.11(10.45)$ & $44 / 53$ & 0.893 \\
Adaptive skills & $38.24(11.7)$ & $40.83(10.56)$ & $37 / 48$ & 0.288 \\
Adaptability & $39.7(10.52)$ & $38.51(12.07)$ & $44 / 53$ & 0.583 \\
Social skills & $34.74(9.2)$ & $35.81(9.79)$ & $27 / 36$ & 0.642 \\
Leadership & $33.32(14.15)$ & $32.65(11.36)$ & $25 / 26$ & 0.750 \\
Activities of daily living & $30.35(11.09)$ & $28.42(10.47)$ & $26 / 26$ & 0.639 \\
Functional communication & $65.56(11.46)$ & $60.29(10.33)$ & $43 / 52$ & $0.023^{*}$ \\
Behavior symptoms index & & & &
\end{tabular}

Interesting findings were that the rates of seizures, tics, and externalizing problems documented by the BASC which were significantly increased in the group of children with FXS of $\mathrm{M}+\mathrm{AI}$. The overall prevalence of seizures in children with FXS in both groups of $\mathrm{M}+\mathrm{AI}$ and $\mathrm{M}-\mathrm{AI}$ was similar to the 10-20\% rate seizures previously reported in FXS (Berry-Kravis 2002; Musumeci et al. 1999).

The pathophysiology of seizures in those with FXS is hypothesized to be related to the imbalance of the excitatory and inhibitory neurotransmitter systems, especially the mGluR5 pathway and the gamma-aminobutyric acid A $\left(\mathrm{GABA}_{\mathrm{A}}\right)$ pathway in the absence of FMRP. There is a lower expression of GABA receptors in the fragile $\mathrm{X}$ knock out (KO) mouse (D'Hulst et al. 2006) and an increased expression of glutamic acid decarboxylase (GAD), the enzyme responsible for GABA synthesis in the KO mouse (El Idrissi et al. 2005). Interestingly, other factors including autoimmunity or immune-mediated responses may influence these pathways leading to seizures. For instance, the presence of autoantibody to GAD was demonstrated in the sera of non-fragile $\mathrm{X}$ patients with early onset of chronic drug-resistant epilepsy leading to loss of GAD and decreased GABA synthesis that ultimately contributed to a lower seizure threshold (McKnight et al. 2005). In addition, autoantibodies to GluR3B-peptide of glutamate/ $\alpha$-amino3-hydroxy-5-methyl-4-isoxazoleproprionic acid (AMPA) receptor subtype 3 or to a peptide of $N$-methyl-D-aspartate (NMDA) receptor subunit $2 \mathrm{~A}$ (NR2A) subunit of gluta-
mate/NMDA receptors have been found to be elevated in non-fragile $X$ patients with epilepsy (Ganor et al. 2005). However, there are no studies of autoimmunity in mothers of children with epilepsy or seizures available. Moreover, the impact of autoimmunity on seizures in individuals with FXS has not been studied and our work provides just the first step in this direction. This study suggests that autoimmunity in the mother may influence the risk of seizures in the offspring with FXS.

A tic disorder has been reported in approximately $20 \%$ in individuals with FXS (Hagerman 2002). The pathophysiology of tic disorders is quite complex. There are genetic and environmental influences that involve a number of brain structures including basal ganglia, cortico-striatothalamo-cortical circuits, dopaminergic, glutamatergic, and the serotoninergic neuronal system (Harris and Singer 2006; Rampello et al. 2006). Although there is familial aggregation in those with Tourette syndrome, the most severe and chronic form of a tic disorder, but family members also share common environmental factors in addition to their similar genetic backgrounds (O'Rourke et al. 2009). The potential role of various abnormal immune-mediated responses followed by different triggers/factors causing or exacerbating tics or Tourette syndrome has been previously reported in conditions including PANDAS, possible involvement of non-streptococcal and viral infection in aggravating tics symptoms, or the presence of different antibodies/auto-antibodies in either sera or against striatal 
structures in human subjects, and animal models, respectively. These antibodies include anti-phospholipid auto-antibodies and antineuronal antibodies (Martino et al. 2009a; Morer et al. 2008; Rampello et al. 2006). There are no studies of other autoimmunity in mothers of children with tics or Tourette syndrome available, although there are family studies that show a higher incidence of Tourette syndrome in the parents and the etiology in a subgroup of those with Tourette syndrome includes autoantibodies against the basal ganglia as mentioned above so this can also be an autoimmune disease itself (Martino et al. 2009b; O'Rourke et al. 2009). Therefore, an increase rate of tics in our study may suggest another potential hypothesis that future studies should take into account of autoimmunity in the mothers or the inheritance of autoimmune tendencies in their offspring with FXS may be related to a higher rate of tics in these children.

Taken together, our findings suggest that future studies should consider how autoimmunity in the mothers may interact with the FMRI mutation to disrupt critical networks in the brain, particularly GABA and glutamate systems or perhaps through other mechanisms leading to clinical seizures, tics, and behavioral problems in their offspring with FXS. Children with FXS born to M + AI may be genetically more prone to produce antibodies that exacerbate an underlying seizure and tic tendency in FXS. This hypothesis requires further prospective study with larger sample sizes.

The weaknesses of our study includes a clinical sample with an assessment of autoimmune disease that is documented only by medical history which can be influenced by poor recall, small numbers of study subjects and the lack of documentation of specific antibodies that may affect the offspring. However, a possible association between the autoimmunity in mothers and medical and neurodevelopmental problems in their children with FXS was assessed years after our routine data collection and therefore was blinded and unbiased regarding autoimmune disease in the mother. Although there were gender differences between both groups of offspring, other characteristics particularly age, molecular data, cognitive abilities, and adaptive functioning were not significantly different between both groups of offspring. The gender difference was accounted for in the analyses using logistic regression and general linear models. However, if we had had more male offspring of $\mathrm{M}+\mathrm{AI}$, it is likely that we would have found more significant differences between the two groups of children because boys with FXS have a higher rate of intellectual and behavioral impairments including autism compared to girls with FXS.

An important limitation of the current study relates to our statistically significant findings (e.g. seizures, tics, and BASC behavioral outcome) among our exploratory/secondary variables. Although these findings suggest specific outcomes to examine in future studies, these statistically significant findings are not adjusted for multiple testing; thus, the overall type I error rate is inflated. Mothers provided data regarding their own medical history and their offspring's behavioral data, it is possible that psychological factors, such as anxiety or depression associated with autoimmune disease or the premutation could have introduced a negative bias in these behavioral ratings. This point, however, raises another potential explanation for our findings, specifically high rates of stress and anxiety associated with raising children with FXS could potentially contribute to a pro-inflammatory environment that may facilitate autoimmunity tendency in the premutation mothers (Stojanovich 2010; Stojanovich and Marisavljevich 2008). The issue regarding whether or not the autoimmune disease occurred during the gestation cannot be accurately assessed with this retrospective data. Therefore, prospectively collected data is needed to investigate risk during pregnancy and biological markers of immune function should be obtained to elucidate this possible intergenerational relationship.

In conclusion, autoimmune disease in mothers was not significantly associated with the presence of ASD in their children with FXS. However, clinical seizures, tics, and behavioral problems were significantly increased in children with FXS born to $\mathrm{M}+\mathrm{AI}$. These data suggest an additional mechanism of seizure and tic exacerbation in FXS related to an intergenerational influence from autoimmunity in the mother.

Acknowledgments This work was supported by National Institute of Health Grants HD036071, and HD02274; Neurotherapeutic Research Institute (NTRI) Grants DE019583, and DA024854; National Institute on Aging Grants AG032119 and AG032115; National Institute of Mental Health Grant MH77554; National Center for Resources UL1 RR024146; and support from the Health and Human Services Administration of Developmental Disabilities Grant 90DD05969. We also thank Antoniya Boyd and Jacky Au from the UC Davis MIND. Institute for their help with data processing and providing some BASC questionnaires to the parents, respectively.

Conflict of interest Randi Hagerman has received funding from Seaside Therapeutics, Roche, Novartis, Neuropharm, Forest, Johnson and Johnson, and Curemark to carry out treatment trials. There are no other conflicts of interest from the authors.

Open Access This article is distributed under the terms of the Creative Commons Attribution Noncommercial License which permits any noncommercial use, distribution, and reproduction in any medium, provided the original author(s) and source are credited.

\section{References}

American Psychiatric Association (2000) Diagnostic and Statistical Manual of Mental Disorders, text revised, 4th edn. American Psychiatric Association, Washington, DC

Ashwood P, Van de Water J (2004) Is autism an autoimmune disease? Autoimmun Rev 3:557-562

Ashwood P, Wills S, Van de Water J (2006) The immune response in autism: a new frontier for autism research. J Leukoc Biol 80:1-15 
Atladottir HO, Pedersen MG, Thorsen P, Mortensen PB, Deleuran B, Eaton WW, Parner ET (2009) Association of family history of autoimmune diseases and autism spectrum disorders. Pediatrics 124:687-694

Berry-Kravis E (2002) Epilepsy in fragile X syndrome. Dev Med Child Neurol 44:724-728

Buskila D, Sarzi-Puttini P (2008) Fibromyalgia and autoimmune diseases: the pain behind autoimmunity. Isr Med Assoc J 10:77-78

Chonchaiya W, Schneider A, Hagerman RJ (2009) Fragile X: a family of disorders. Adv Pediatr 56:165-186

Coffey SM, Cook K, Tartaglia N, Tassone F, Nguyen DV, Pan R, Bronsky HE, Yuhas J, Borodyanskaya M, Grigsby J, Doerflinger M, Hagerman PJ, Hagerman RJ (2008) Expanded clinical phenotype of women with the FMR1 premutation. Am J Med Genet A 146:1009-1016

Comi AM, Zimmerman AW, Frye VH, Law PA, Peeden JN (1999) Familial clustering of autoimmune disorders and evaluation of medical risk factors in autism. J Child Neurol 14:388-394

Croen LA, Grether JK, Yoshida CK, Odouli R, Van de Water J (2005) Maternal autoimmune diseases, asthma and allergies, and childhood autism spectrum disorders: a case-control study. Arch Pediatr Adolesc Med 159:151-157

D'Hulst C, De Geest N, Reeve SP, Van Dam D, De Deyn PP, Hassan BA, Kooy RF (2006) Decreased expression of the GABAA receptor in fragile X syndrome. Brain Res 1121:238-245

Dalton P, Deacon R, Blamire A, Pike M, McKinlay I, Stein J, Styles P, Vincent A (2003) Maternal neuronal antibodies associated with autism and a language disorder. Ann Neurol 53:533-537

Delneste Y, Herbault N, Galea B, Magistrelli G, Bazin I, Bonnefoy JY, Jeannin P (1999) Vasoactive intestinal peptide synergizes with TNF-alpha in inducing human dendritic cell maturation. J Immunol 163:3071-3075

Di Franco M, Iannuccelli C, Valesini G (2010) Neuroendocrine immunology of fibromyalgia. Ann N Y Acad Sci 1193:84-90

El Idrissi A, Ding XH, Scalia J, Trenkner E, Brown WT, Dobkin C (2005) Decreased GABA(A) receptor expression in the seizureprone fragile X mouse. Neurosci Lett 377:141-146

Enstrom AM, Van de Water JA, Ashwood P (2009) Autoimmunity in autism. Curr Opin Investig Drugs 10:463-473

Ganor Y, Goldberg-Stern H, Lerman-Sagie T, Teichberg VI, Levite M (2005) Autoimmune epilepsy: distinct subpopulations of epilepsy patients harbor serum autoantibodies to either glutamate/AMPA receptor GluR3, glutamate/NMDA receptor subunit NR2A or double-stranded DNA. Epilepsy Res 65:11-22

Garcia-Nonell C, Ratera ER, Harris S, Hessl D, Ono MY, Tartaglia N, Marvin E, Tassone F, Hagerman RJ (2008) Secondary medical diagnosis in fragile $\mathrm{X}$ syndrome with and without autism spectrum disorder. Am J Med Genet A 146A:1911-1916

Greco CM, Tassone F, Garcia-Arocena D, Tartaglia N, Coffey SM, Vartanian TK, Brunberg JA, Hagerman PJ, Hagerman RJ (2008) Clinical and neuropathologic findings in a woman with the FMR1 premutation and multiple sclerosis. Arch Neurol 65:1114-1116

Hagerman RJ (2002) Physical and behavioral phenotype. In: Hagerman RJ, Hagerman PJ (eds) Fragile X syndrome: diagnosis, treatment and research, 3rd edn edn. The Johns Hopkins University Press, Baltimore, pp 3-109

Hagerman RJ, Rivera SM, Hagerman PJ (2008) The fragile X family of disorders: a model for autism and targeted treatments. Curr Pediatr Rev 4:40-52

Harris K, Singer HS (2006) Tic disorders: neural circuits, neurochemistry, and neuroimmunology. J Child Neurol 21:678-689

Harris SW, Hess1 D, Goodlin-Jones B, Ferranti J, Bacalman S, Barabato I, Tassone F, Hagerman PJ, Herman K, Hagerman RJ (2008) Autism profiles of males with fragile X syndrome. Am J Mental Retard 113:427-438
Kaufmann WE, Cortell R, Kau AS, Bukelis I, Tierney E, Gray RM, Cox C, Capone GT, Stanard P (2004) Autism spectrum disorder in fragile $\mathrm{X}$ syndrome: communication, social interaction, and specific behaviors. Am J Med Genet 129A:225-234

Le Couteur A, Rutter M, Lord C, Rios P, Robertson S (1989) Autism diagnostic interview: a standardized investigator-based instrument. J Autism Dev Disord 19:363-387

Loesch DZ, Bui QM, Dissanayake C, Clifford S, Gould E, BulhakPaterson D, Tassone F, Taylor AK, Hessl D, Hagerman R, Huggins RM (2007) Molecular and cognitive predictors of the continuum of autistic behaviours in fragile X. Neurosci Biobehav Rev 31:315-326

Lord C, Risi S, Lambrecht L, Cook EH Jr, Leventhal BL, DiLavore PC, Pickles A, Rutter M (2000) The autism diagnostic observation schedule-generic: a standard measure of social and communication deficits associated with the spectrum of autism. J Autism Dev Disord 30:205-223

Martin LA, Ashwood P, Braunschweig D, Cabanlit M, Van de Water J, Amaral DG (2008) Stereotypies and hyperactivity in rhesus monkeys exposed to $\mathrm{IgG}$ from mothers of children with autism. Brain Behav Immun 22:806-816

Martino D, Dale RC, Gilbert DL, Giovannoni G, Leckman JF (2009a) Immunopathogenic mechanisms in Tourette syndrome: a critical review. Mov Disord 24:1267-1279

Martino D, Defazio G, Giovannoni G (2009b) The PANDAS subgroup of tic disorders and childhood-onset obsessive-compulsive disorder. J Psychosom Res 67:547-557

McKnight K, Jiang Y, Hart Y, Cavey A, Wroe S, Blank M, Shoenfeld Y, Vincent A, Palace J, Lang B (2005) Serum antibodies in epilepsy and seizure-associated disorders. Neurology 65:1730-1736

Micali N, Chakrabarti S, Fombonne E (2004) The broad autism phenotype: findings from an epidemiological survey. Autism 8:21-37

Money J, Bobrow NA, Clarke FC (1971) Autism and autoimmune disease: a family study. J Autism Child Schizophr 1:146-160

Morer A, Lazaro L, Sabater L, Massana J, Castro J, Graus F (2008) Antineuronal antibodies in a group of children with obsessivecompulsive disorder and Tourette syndrome. J Psychiatr Res 42:64-68

Mouridsen SE, Rich B, Isager T, Nedergaard NJ (2007) Autoimmune diseases in parents of children with infantile autism: a casecontrol study. Dev Med Child Neurol 49:429-432

Mullen EM (1995) Mullen scales of early learning. American Guidance Service, Circle Pines

Musumeci SA, Hagerman RJ, Ferri R, Bosco P, Dalla Bernardina B, Tassinari CA, De Sarro GB, Elia M (1999) Epilepsy and EEG findings in males with fragile X syndrome. Epilepsia 40:10921099

O'Rourke JA, Scharf JM, Yu D, Pauls DL (2009) The genetics of Tourette syndrome: a review. J Psychosom Res 67:533-545

Papi G, Uberti ED, Betterle C, Carani C, Pearce EN, Braverman LE, Roti E (2007) Subclinical hypothyroidism. Curr Opin Endocrinol Diabetes Obes 14:197-208

Poppe K, Glinoer D (2003) Thyroid autoimmunity and hypothyroidism before and during pregnancy. Hum Reprod Update 9:149161

Rampello L, Alvano A, Battaglia G, Bruno V, Raffaele R, Nicoletti F (2006) Tic disorders: from pathophysiology to treatment. J Neurol 253:1-15

Reynolds CR, Kamphaus RW (1992) BASC Behavior Assessment System for Children Manual. American Guidance Service, Circle Pines

Reynolds CR, Kamphaus RW (2004) BASC-2 behavior assessment system for children, 2nd edn. AGS Publishing, Circle Pines

Rodriguez-Revenga L, Madrigal I, Pagonabarraga J, Xuncla M, Badenas C, Kulisevsky J, Gomez B, Mila M (2009) Penetrance of 
FMR1 premutation associated pathologies in fragile $\mathrm{X}$ syndrome families. Eur J Hum Genet 17:1359-1362

Rogers SJ, Wehner EA, Hagerman RJ (2001) The behavioral phenotype in fragile $\mathrm{X}$ : symptoms of autism in very young children with fragile X syndrome, idiopathic autism, and other developmental disorders. J Dev Behav Pediatr 22:409-417

Singer HS, Morris CM, Williams PN, Yoon DY, Hong JJ, Zimmerman AW (2006) Antibrain antibodies in children with autism and their unaffected siblings. J Neuroimmunol 178:149-155

Sparrow SS, Cicchetti DV, Balla DA (2005) Vineland adaptive behavior scales, 2nd edn. AGS Publishing, Circle Pines

Staines DR (2004) Is fibromyalgia an autoimmune disorder of endogenous vasoactive neuropeptides? Med Hypotheses 62:665-669

Stojanovich L (2010) Stress and autoimmunity. Autoimmun Rev 9:A271-A276

Stojanovich L, Marisavljevich D (2008) Stress as a trigger of autoimmune disease. Autoimmun Rev 7:209-213

Sweeten TL, Bowyer SL, Posey DJ, Halberstadt GM, McDougle CJ (2003) Increased prevalence of familial autoimmunity in probands with pervasive developmental disorders. Pediatrics 112:e420

Tassone F, Hagerman RJ, Taylor AK, Gane LW, Godfrey TE, Hagerman PJ (2000) Elevated levels of FMR1 mRNA in carrier males: a new mechanism of involvement in the fragile- $X$ syndrome. Am J Hum Genet 66:6-15

Tassone F, Pan R, Amiri K, Taylor AK, Hagerman PJ (2008) A rapid polymerase chain reaction-based screening method for identification of all expanded alleles of the fragile X (FMR1) gene in newborn and high-risk populations. J Mol Diagn 10:43-49

Thorndike RL, Hagen E, Sattler J (1986) Stanford-Binet intelligence scale, 4th edn. Riverside Publishing, Itasca

Ulff-Moller CJ, Jorgensen KT, Pedersen BV, Nielsen NM, Frisch M (2009) Reproductive factors and risk of systemic lupus erythematosus: nationwide cohort study in Denmark. J Rheumatol 36:1903-1909

Wang LW, Berry-Kravis E, Hagerman RJ (2010) Fragile X: leading the way for targeted treatments in autism. Neurotherapeutics 7:264-274

Wechsler D (1991) Wechsler intelligence scale for children, (WISC-III), 3rd edn. The Psychological Corporation, San Antonio

Wechsler D (1997) Wechsler adult intelligence scale: administration and scoring manual, 3rd edn. Harcourt Assessment, San Antonio

Wechsler D (1999) Wechsler abbreviated scale of intelligence (WASI). Harcourt Assessment, San Antonio

Wechsler D (2002) Wechsler preschool and primary scale of intelligence, 3rd edn. The Psychological Corporation, San Antonio

Wechsler D (2003) Wechsler intelligence scale for children, 4th edn. Harcourt Assessment., San Antonio

Zhang L, Coffey S, Lua LL, Greco CM, Schafer JA, Brunberg J, Borodyanskaya M, Agius MA, Apperson M, Leehey M, Tartaglia N, Tassone F, Hagerman PJ, Hagerman RJ (2009) FMR1 premutation in females diagnosed with multiple sclerosis. J Neurol Neurosurg Psychiatry 80:812-814 